\title{
Large Earthquake Prediction Methods
}

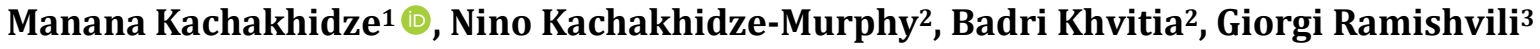 \\ ${ }^{1}$ Saint Andrew the First-Called Georgian University, Tbilisi, Georgia \\ ${ }^{2}$ Ivane Javakhishvili Tbilisi State University, Tbilisi, Georgia \\ ${ }^{3}$ Ilia State University, Tbilisi, Georgia \\ Email: kachakhidzem@gmail.com
}

How to cite this paper: Kachakhidze, M., Kachakhidze-Murphy, N., Khvitia, B. and Ramishvili, G. (2019) Large Earthquake Prediction Methods. Open Journal of Earthquake Research, 8, 239-254.

https://doi.org/10.4236/ojer.2019.84014

Received: September 25, 2019

Accepted: November 4, 2019

Published: November 7, 2019

Copyright () 2019 by author(s) and Scientific Research Publishing Inc. This work is licensed under the Creative Commons Attribution International License (CC BY 4.0).

http://creativecommons.org/licenses/by/4.0/

\begin{abstract}
At the present time rather diverse and interesting papers are published on the basis of ground-based and satellite data of earth VLF/LF and ULF electromagnetic (EM) emissions observed during earthquake preparation period. These phenomena are detectable both at laboratory and geological scale. Today in some seismic active countries of the world the network for collecting VLF/LF electromagnetic emissions generated during the process of the earthquake preparation has been organized. Permanent monitoring of frequency spectrum of earth VLF/LF electromagnetic emissions might turn out very useful with the view of prediction of large $M \geq 5$ inland earthquakes. To prove the prediction capabilities of earth electromagnetic emissions authors have used avalanche-like unstable model of fault formation and an analogous model of electromagnetic contour, synthesis of which, is rather harmonious. According to the opinion of the authors EM emissions observed during earthquake preparation period are more universal and reliable than other earthquake indicators. In the presented paper, the possible methods of the large earthquake prediction are offered on the base of the European Network of Electromagnetic Radiation (INFREP) data existent before Crete earthquake with $\mathrm{M}=5.6$ (25/05/2016, 08:36:13 UTC) earthquake. Offered methods are capable of simultaneous determination of all three parameters necessary for incoming $M \geq 5$ inland large earthquake prediction (magnitude, epicenter and time of occurring) with certain accuracy.
\end{abstract}

\section{Keywords}

Earthquake, Precursor, VLF/LF Radio-Waves

\section{Introduction}

Studies of earthquake problems in the world were especially intensified from the second half of the last century, since alongside theoretical studies it became 
possible to carry out high level laboratory and satellite experiments [1]-[14].

Thanks to them, various anomalous changes of geophysical fields have been revealed in lithosphere as well as in atmosphere and ionosphere during the earthquake preparation period.

Geophysical fields related with earthquake preparation and occurrence can be conditionally divided into earthquake triggering factors [15] [16], earthquake indicators [17] [18] and earthquake precursors [19].

Earthquake is the geological phenomena. In addition, it is the well-known geological model, which describes the avalanche-unstable process of fault origination and finally, main fault formation process in the focus of incoming earthquake [20].

Because, the geophysical field, which is studied by the scientists during earthquake problem searching, has to precisely express above mentioned geological model and in connect with it, should analytically describe the complex process of fault formation from the beginning of micro cracks appearing up to main fault formation and restore the equilibrium in the focus.

It is precisely such a geophysical field that must be considered as an earthquake precursor. All other fields, which only qualitatively express the processes taking place in focus and are perturbed thanks to them, can be considered as an indicator.

Studies have shown that on Earth's surface during the earthquake preparation period VLF /LF radiation is observed. In recent decades in some seismic active countries of the world, the network for detection of VLF/LF radio signals has been organized. The role of above mentioned electromagnetic emissions networks is very important because it enriched science with invaluable information and made the searching of earthquake forecasting problem far more wide-scale and integral.

Experimental studies in the direction of searching of EM VLF/LF radiation existent before earthquake have shown that: 1 ) in the period of large earthquake preparation, noted radiation begins a few weeks before the earthquake; 2) for the spectrum of existing electromagnetic emissions the following sequence of frequencies is characteristic: $\mathrm{MHz}, \mathrm{kHz} ; 3$ ) both these emissions from the beginng up to end are accompanied by ULF radiation; 4) in most cases, a few days before the earthquake, so-called emissions "silence" take place. During "silence" electromagnetic field radiation almost does not exist or it is reduced; 5) "silence" of EM emissions is followed by earthquake [11] [21] [22].

The existence of this type of VLF/LF field in the epicenter area during the earthquake preparation period and its tendency to change indicate that:

1) The emitted body of VLF/LF EM emissions should be in the focus,

2) The regularity of changes of the VLF/LF EM emissions in the epicentral area should be caused by changes of length of this body;

Based on these considerations, the model of EM emissions generation fixed before earthquake was developed [19].

In the work of our scientific team, the frequency of electromagnetic radiation existent during the earthquake preparation period is analytically connected with 
the fault length originated in the incoming earthquake focus (1) [19]:

$$
l=\beta \frac{c}{\omega}
$$

where $\omega$ is the frequency of existent electromagnetic emissions, $c$ is the light speed, $\beta$ is the characteristic coefficient of geological medium (it approximately equals to 1 ).

Based on this work, the theoretical methods of earthquake prediction were created [23]. The relevant results were reported at the EGU Assembly in 2016 [24].

In this presented work we have tried to check earthquake prediction possibilities on the base of the INFREP retrospective data and abovementioned papers. At this stage of study we do not discuss foreshocks and aftershocks series.

As noted above, the theory created by our group [23] is based on the analysis of frequencies of electromagnetic radiation existing in the earthquake preparation period.

Because INFREP network fixes every minute amplitudes of 10 different frequencies electromagnetic radiation, based on INFREP data, it was calculated and used every minute frequency numerical values transformed by the normal distribution of Gauss [25].

\section{Discussion}

\subsection{Determination of the Incoming Earthquake Magnitude}

As it is known, earthquake magnitude is measured based on seismic waves data and only after the earthquake, because, before earthquake we do not have information about parameters required to determine the magnitude.

In this regard, electromagnetic radiation has different features: it arises during the earthquake preparation period, exists until the last aftershock, and more importantly, we can fix it as soon as it originates.

This is the main advantage of the electromagnetic emissions because before the earthquake, in advance, by EM emissions records, it is possible to determine the length of the fault in the focus (1) [23] as well as magnitude $(2,3)$ of the incoming earthquake:

$$
\begin{gathered}
\lg l=0.6 * M_{S}-2.5 \\
M_{w}=4.38+1.49 * \log l
\end{gathered}
$$

According to the baseline frequencies of the INFREP receivers, by the abovementioned (1), (2) and (3) formulas, we calculated the fault lengths and magnitudes. In order easily to mention the frequency channels in this article, they are symbolically marked with letters (Table 1).

The following classifications were made: channels that indicate the $M \geq 5$ earthquakes corresponding frequencies (C, D, E, F, G) are considered as "strong" channels, and "weak" channels, which frequencies correspond to $4.2<$ $M<5.5$ earthquakes (H, I, J, K, L) (Table 1). 
Table 1. INFREP frequency channels with relevant fault lengths and magnitudes.

\begin{tabular}{ccccc}
\hline frequency $(\mathrm{Hz})$ & channels & fault length $(\mathrm{m})$ & $\mathrm{Ms}$ & $\mathrm{Mw}$ \\
\hline 20,270 & C & 14,800 & 6.1 & 6.1 \\
20,900 & $\mathrm{D}$ & 14,354 & 6.1 & 6.1 \\
23,400 & $\mathrm{E}$ & 12,820 & 6.0 & 6.0 \\
37,500 & $\mathrm{~F}$ & 8000 & 5.7 & 5.7 \\
45,900 & $\mathrm{G}$ & 6535 & 5.5 & 5.6 \\
153,000 & H & 1960 & 4.7 & 4.8 \\
162,000 & $\mathrm{I}$ & 1851 & 4.6 & 4.8 \\
183,000 & J & 1639 & 4.5 & 4.7 \\
216,000 & K & 1388 & 4.4 & 4.6 \\
270,000 & L & 1111 & 4.2 & 4.4
\end{tabular}

The calculations show that the frequencies are highly sensitive to the fault length. Therefore, the frequency of electromagnetic radiation allows us to measure an earthquake magnitude much more precisely than it measures today. Seismologists and focus physicists should decide in the future whether it is necessary to determine magnitude with such high accuracy.

\subsection{Separation of the Active Channel}

In order to possible predictability of the large earthquakes, studies have been conducted for Crete earthquake with $M=5.6$ (25/05/2016, 08:36:13 UTC) for period 04.04.00:00-16.06.23:59:00 (73 days).

As known, avalanche - unstable process of fault formation is important stage in the earthquake preparation period [20]. The avalanche unstable process is exactly the process during which the significant changes of geophysical fields take place in the focus. Because of LAI (lithosphere-atmosphere-ionosphere) coupling system, these changes reveal themselves as earthquake precursors or indicators on the earth surface, atmosphere and ionosphere.

Duration of avalanche process of fault formation mainly varies from $10-14$ days to 1 month before earthquake and it depends on geological peculiarities of the region [20]. According to our theory [23] [24], EM radiation is the main precursor of earthquake. Therefore, the earthquake preparation process should be reflected in the INFREP records.

Because we searched the Crete earthquake based on retrospective data, we had an opportunity to study the full earthquake preparation picture during the reviewed period.

For considered period, amplitudes and frequencies graphs have been created separately for receiver all channels. As expected, graphs for these two parameters unequivocally are identical, because we represent the amplitude graphs for two strong channels: F $(37,500 \mathrm{~Hz})$ and C $(20,270 \mathrm{~Hz})$ (Figure 1, Figure 2 Earthquake occurring moment is noted by the arrow). 


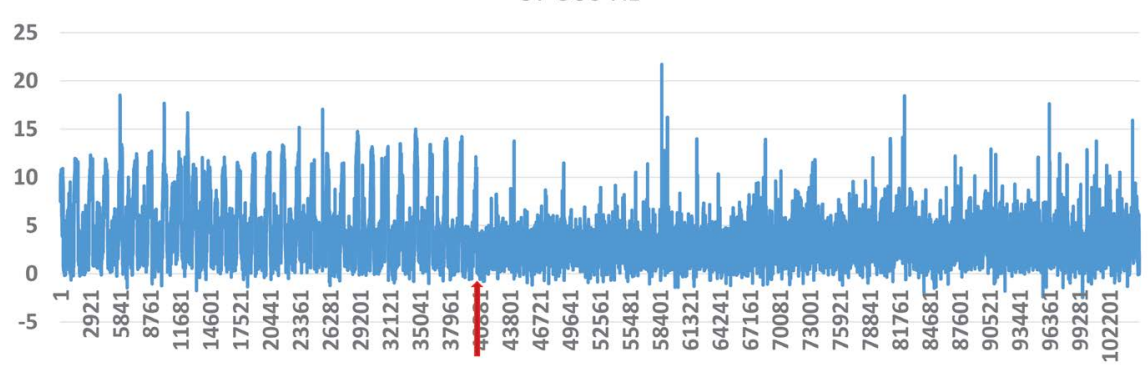

Figure 1. 73-days amplitude graph for F channel.

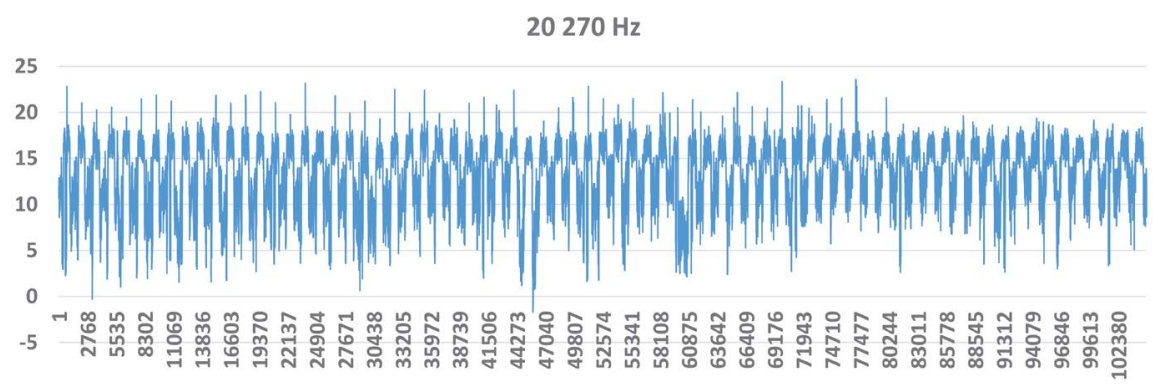

Figure 2. 73-days amplitude graph for $\mathrm{C}$ channel.

By discussion of the graphs we identified their general characteristic feature on all 10 channels, except $\mathrm{F}(37,500 \mathrm{~Hz})$, during the reviewed period, diurnal periodic variations are clearly expressed. We have such variations in the $\mathrm{F}$ channel recordings too, but till some period, in particular, up to 02.05 , after which the anomalous process starts, indicating that the avalanche unstable process of fault formation already began in earthquake preparation period.

In order to make the ongoing processes more visible, additionally we created graphs of several days for all 10 channels data. Figure 3 and Figure 4 show the graphs of exactly 8-days data which consist with the beginning moment of avalanche unstable process on the same $37,500 \mathrm{~Hz}$ and $20,270 \mathrm{~Hz}$ channels.

The general analysis of 8-days graphs has shown that during the large earthquake preparation period, not every channel, among them strong, can "see" the earthquake preparation process. It should be assumed that this process is reflected in the channel, in our case F $(37,500 \mathrm{~Hz})$ "active" channel, on which the stages of avalanche process of fault formation are expressed and based on data of which should be made predictable conclusions in the future.

Because our goal is to find large earthquake forecasting methods (on example of Crete earthquake), we used only so-called "strong" channels (C-G, Table 1) data.

As shown above, the $\mathrm{F}(37,500 \mathrm{~Hz})$ "active" channel was detected by analyzing the full 73-days retrospective data. However, in case of the earthquake monitoring process, when the conclusions should be made in advance, before the earthquake, it is obvious that such an approach will not work.

Let us recall that in relatively early stages of the earthquake preparation, the origin and locking of small chaotic orientation cracks take place. Later, since the 


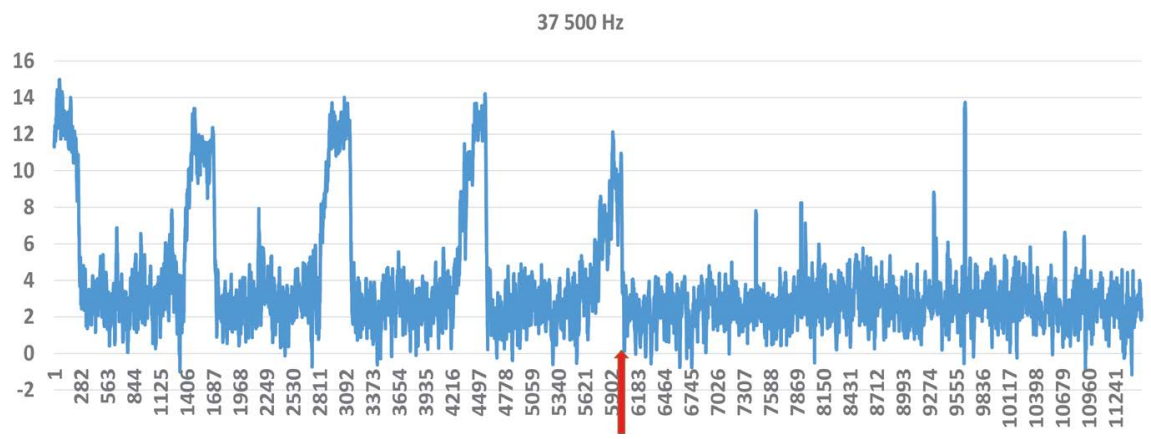

Figure 3. F channel amplitude graph for 28 April-5 May.

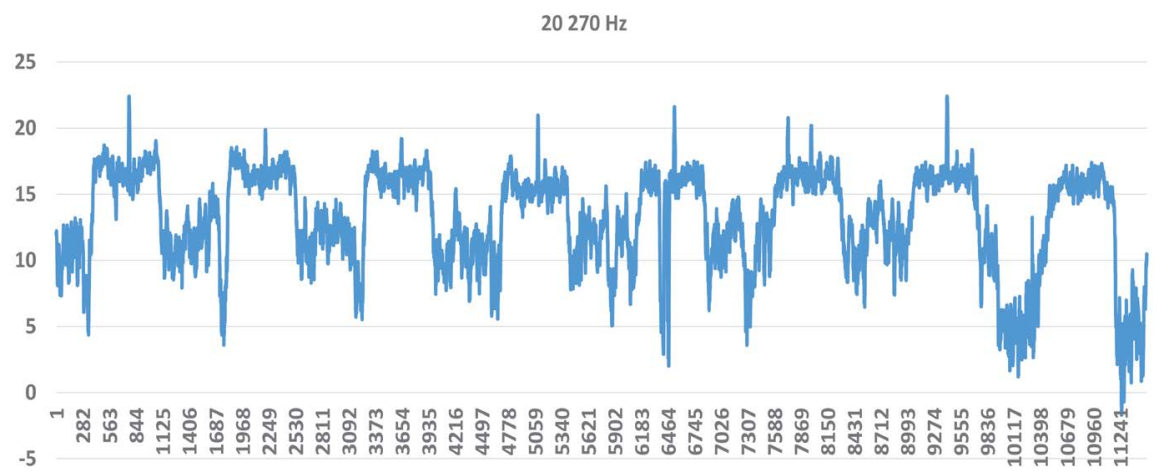

Figure 4. C channel amplitude graph for 28 April-5 May.

beginning of avalanche process of fault formation, the cracks start oriented locating in parallel planes to each other on so-called "cracked strip", which is followed by their joining and formation of main fault at the last stage of earthquake preparation [20].

If any frequency channel actually reflects the earthquake preparation, it is natural that the relevant geological process should be reflected in the frequency data since there is an analytical connection between the frequency of EM radiation and the fault length in the earthquake focus [19].

For this reason, we separately calculated the total lengths of every minute cracks corresponding to $\mathrm{C}-\mathrm{G}$ frequency channels towards the length relevant to channel baseline frequency. After we computed the average daily values of these significances. The results of the calculation are given in Table 2 .

In order to make the results more visible, the same results are shown in Figure 5.

It turned out that the $F(37,500 \mathrm{~Hz})$ channel is most active and the $\mathrm{G}(45,900$ $\mathrm{Hz}$ ) channel is less active to the earthquake preparation process, as average daily value of the total lengths of the cracks (in percentages) were the maximum for these two channels. This means that from discussed 5 channels, only two, with above mentioned frequencies, described the earthquake preparation process. In this case, according to Table 1, the magnitude of incoming earthquake should be between 5.5 and 5.7 (Crete earthquake magnitude is really estimated as $\mathrm{M}=5.6$ ).

Thus, in case of Crete earthquake about 50 days before the earthquake, it is 
Table 2. Average daily values of cracks total lengths in percentages for C-G channels.

\begin{tabular}{|c|c|c|c|c|c|}
\hline Data & $\begin{array}{c}20,270-\mathrm{C} \\
(\mathrm{Hz})\end{array}$ & $\begin{array}{c}20,900-\mathrm{D} \\
(\mathrm{Hz})\end{array}$ & $\begin{array}{c}23,400-\mathrm{E} \\
(\mathrm{Hz})\end{array}$ & $\begin{array}{c}37,500-\mathrm{F} \\
(\mathrm{Hz})\end{array}$ & $\begin{array}{c}45,900-\mathrm{G} \\
(\mathrm{Hz})\end{array}$ \\
\hline 4 April & 72.9 & 72.3 & 73.7 & 93.7 & 87.2 \\
\hline 5 & 71.7 & 71.8 & 73.6 & 93.8 & 86.9 \\
\hline 6 & 71.8 & 70.8 & 73.4 & 93.3 & 88.2 \\
\hline 7 & 71.7 & 74 & 73.4 & 94.1 & 86.9 \\
\hline 8 & 72.9 & 73.2 & 73.3 & 93.5 & 87.4 \\
\hline 9 & 72.5 & 71.8 & 73.3 & 93.3 & 87 \\
\hline 10 & 72.2 & 71.9 & 73.4 & 93.5 & 87.3 \\
\hline 11 & 72.8 & 73.1 & 73.7 & 92.7 & 87.1 \\
\hline 12 & 72.6 & 80.3 & 73.9 & 92.7 & 87.5 \\
\hline 13 & 72 & 78.8 & 75.1 & 93.3 & 87.9 \\
\hline 14 & 71.8 & 80.3 & 75.9 & 93.6 & 87 \\
\hline 15 & 72.2 & 79.2 & 74.5 & 93.7 & 87.4 \\
\hline 16 & 71.8 & 70.1 & 74.3 & 94 & 87.2 \\
\hline 17 & 71.8 & 72 & 74.6 & 93.8 & 87.5 \\
\hline 18 & 72.3 & 72.1 & 76.2 & 93.5 & 87.4 \\
\hline 19 & 71.4 & 71.9 & 76.8 & 93.5 & 87.2 \\
\hline 20 & 71.8 & 71.7 & 76.7 & 93.2 & 88.3 \\
\hline 21 & 71.4 & 72.1 & 74.4 & 94.2 & 87.2 \\
\hline 22 & 71.9 & 72.2 & 73.4 & 94.2 & 87.5 \\
\hline 23 & 71.8 & 72.1 & 73.5 & 94.8 & 87.2 \\
\hline 24 & 73.7 & 72.3 & 73.9 & 94.1 & 87.6 \\
\hline 25 & 72.8 & 72.2 & 73.7 & 94 & 87.6 \\
\hline 26 & 72.2 & 71.8 & 73.7 & 94.1 & 87.7 \\
\hline 27 & 71.1 & 74.4 & 73.7 & 94.3 & 88.6 \\
\hline 28 & 71.2 & 72 & 73.6 & 93.8 & 88 \\
\hline 29 & 70.8 & 72 & 73.3 & 94.2 & 87.2 \\
\hline 30 & 71.2 & 72 & 73.4 & 94.3 & 87.4 \\
\hline 1 May & 71.6 & 72.1 & 73.5 & 94.5 & 88.1 \\
\hline 2 & 71.8 & 73.4 & 73.7 & 95.2 & 88.1 \\
\hline 3 & 71.2 & 71.6 & 73.5 & 95.9 & 87.7 \\
\hline 4 & 71.8 & 73.2 & 75 & 95.9 & 90 \\
\hline 5 & 74.9 & 76.5 & 78.4 & 96.1 & 89 \\
\hline 6 & 71.5 & 72.7 & 74 & 95.8 & 87.5 \\
\hline 7 & 71.1 & 72.3 & 73.8 & 95.9 & 87.1 \\
\hline 8 & 71.3 & 72.3 & 73.8 & 96.2 & 87.3 \\
\hline
\end{tabular}




\section{Continued}

\begin{tabular}{|c|c|c|c|c|c|}
\hline 9 & 72.8 & 72.3 & 75.8 & 96.1 & 88.1 \\
\hline 10 & 71.1 & 71.9 & 77.5 & 95.9 & 87.5 \\
\hline 11 & 71.1 & 72.8 & 77.2 & 95.6 & 87.4 \\
\hline 12 & 70.7 & 71.8 & 76.4 & 95.7 & 87.3 \\
\hline 13 & 70.9 & 73.5 & 77.2 & 95.9 & 88.1 \\
\hline 14 & 70.6 & 72.2 & 77 & 95.8 & 87.7 \\
\hline 15 & 74.1 & 76.1 & 81.2 & 95.6 & 89.1 \\
\hline 16 & 73.1 & 72.4 & 79.9 & 95.6 & 89 \\
\hline 17 & 71.4 & 68.4 & 76.6 & 95.5 & 88 \\
\hline 18 & 71.2 & 71.8 & 76.8 & 95.8 & 89.3 \\
\hline 19 & 71.2 & 72.5 & 77.2 & 95.4 & 88.3 \\
\hline 20 & 71.6 & 72.8 & 77 & 95 & 88.2 \\
\hline 21 & 70.9 & 72.1 & 76.9 & 95.1 & 88.3 \\
\hline 22 & 70.9 & 73.1 & 77.3 & 95.2 & 88 \\
\hline 23 & 72.1 & 72.3 & 77.6 & 94.7 & 88.3 \\
\hline 24 & 71 & 72 & 76.9 & 93.8 & 88.5 \\
\hline 25 & 70.9 & 74.9 & 76.7 & 95.2 & 89.6 \\
\hline 26 & 70.5 & 69.8 & 77.1 & 95.3 & 88.4 \\
\hline 27 & 70.4 & 72 & 76.9 & 94.8 & 88 \\
\hline 28 & 70.9 & 73.3 & 76.9 & 94.5 & 88.5 \\
\hline 29 & 70.6 & 71.9 & 77.2 & 94.5 & 88.1 \\
\hline 30 & 71.8 & 71.7 & 77.8 & 93.8 & 88.4 \\
\hline 31 & 70.8 & 71.9 & 77.8 & 93.9 & 88.1 \\
\hline 1 June & 70.5 & 71.8 & 76.9 & 95.2 & 89.5 \\
\hline 2 & 70.8 & 71.9 & 77 & 95.4 & 88.4 \\
\hline 3 & 70.8 & 71.9 & 77.2 & 95 & 88 \\
\hline 4 & 70.8 & 71.8 & 76.5 & 95.1 & 88.2 \\
\hline 5 & 71.1 & 71.9 & 76.8 & 94.6 & 88.1 \\
\hline 6 & 72.2 & 71.8 & 76.8 & 94.7 & 88.3 \\
\hline 7 & 70.6 & 71.8 & 76.8 & 94.6 & 88.3 \\
\hline 8 & 70.8 & 72.1 & 77.1 & 94.5 & 89.3 \\
\hline 9 & 71.1 & 72 & 76.9 & 94.7 & 88.8 \\
\hline 10 & 71.3 & 71.8 & 76.7 & 94.7 & 88.8 \\
\hline 11 & 70.7 & 71.8 & 77.1 & 95.7 & 88 \\
\hline 12 & 70.8 & 72.2 & 77.2 & 95.5 & 88 \\
\hline 13 & 71.6 & 71.7 & 77.1 & 94.3 & 88.1 \\
\hline 14 & 70.5 & 71.7 & 77.2 & 94.5 & 88.4 \\
\hline 15 & 70.9 & 71.5 & 77.5 & 94.5 & 89.4 \\
\hline
\end{tabular}




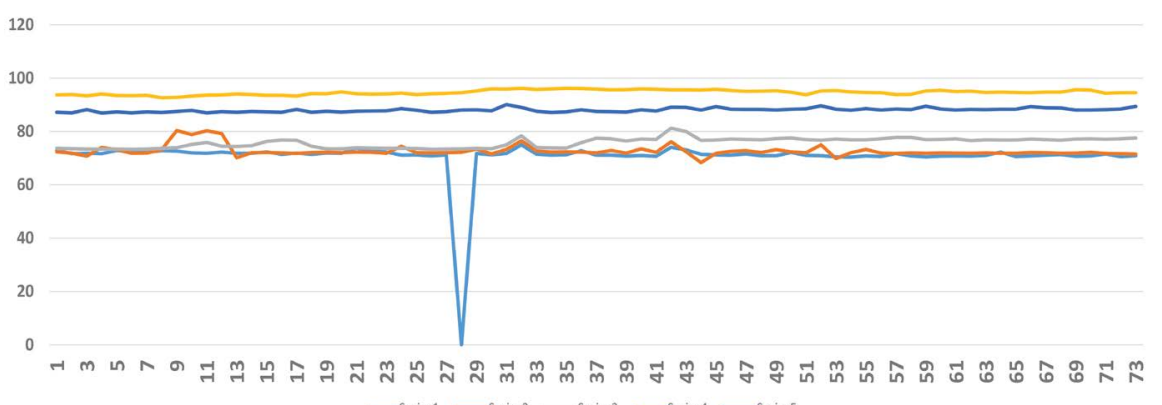

Figure 5. Average daily values of cracks total lengths in percentages for C-G channels.

possible to determine the active "cracked strip" on which the main fault is formed in the future and the earthquake occurs. That method of revealing of the active channel will be appropriate for the earthquake preparation process monitoring because such advantage of cracks total length is appeared just since the first records.

During monitoring, step-by-step, there also is possibility to check the obtained result once again, on the active channel, before the earthquake, the avalanche process of fault formation described by geological model should appear in frequency data [20].

Since, in case of discussed earthquake, only F $(37,500 \mathrm{~Hz})$ frequency channel meets both conditions: for this channel the average daily value of the total lengths of the cracks is maximal by per cent and an avalanche process of fault formation appears only on $\mathrm{F}(37,500 \mathrm{~Hz})$ channel. Obviously, to predict the earthquake, we must rely only on the data of this channel.

It is known that the logical end of avalanche process of fault formation is the final stage of earthquake preparation when, at the expense of cracks joining in the focus of incoming earthquake, the main fault forms. This means that (in the case of discussed earthquake), it is expected to form the main fault with the length appropriate to $\mathrm{F}(37,500 \mathrm{~Hz})$ frequency.

By the Formula (1), expected length of the main fault, should be 8000 meters, but in case of monitoring, it is possible to adjust this numerical value according to frequency significances.

As above said, knowledge of the length of the main fault allow us to determine incoming earthquake magnitude in advance, approximately 50 days before earthquake by (2) and (3) formulas.

\subsection{Possibilities of Determination of the Preparation Area and Epicenter of Incoming Earthquake}

Preliminary assessment of the magnitude, approximately 50 days before incoming earthquake (on example of Crete earthquake), gives us an opportunity to quantify the preparation area of incoming earthquake by (4) formula [26]:

$$
R \approx 10^{0.43 M}
$$

where $R$ is measured in $\mathrm{km}$. 
In addition, epicentral area must have a positive potential [19]. Obviously, bad weather or any technogenic process can be the reason for changing of the potential sign of the earth's local area, but it is not a problem to filter the appropriate field. As soon as the active frequency channel is detected, from the points selected around the receiver, where EM emissions are fixed, by the Direction-finding method, it is possible to define the incoming earthquake epicenter.

In order to specify the location of epicenter, we must take into account the data of magnetic and telluric fields, quality of changes of medium geoelectric heterogeneity, TEC anomaly and other parameters that reveal themselves during earthquake preparation period [2] [6] [10] [27] [28] [29] [30] [31]. It is not excluded to determine the direction of fault in advance. However, these issues should be worked out and be agreed with earthquake focus physics experts.

Thus, it turned out that revealing of active channel is important for making of prognostic conclusions about not only incoming earthquake magnitude (see 2.2) but epicenter too.

\subsection{Possibilities of Determination of Incoming Earthquake Occurring Time}

As above said, in case of Crete earthquake, only the F $(37,500 \mathrm{~Hz})$ active channel reflects the earthquake preparation process. Therefore, through the data of this channel we tried to determine the third parameter, the incoming earthquake time of occurring required for earthquake prediction.

It must note in advance, that from the EM emissions records it can be easily excluded VLF radiation of cosmic origination. In the case of considered earthquake, the "cracked strip", about 50 days prior to earthquake, continuously radiates the frequency approximately equal to frequency at the earthquake occurring moment. As known, the magnetosphere VLF radiation exists in perturbed geomagnetic conditions but these perturbations have no continuous character for 50 days. Therefore, it is easy to separate VLF radiation of the cosmic origin from EM radiation caused by earthquake preparation process.

If any frequency graph shows that the anomalous picture lasts for more than a week, it is possible to assume that it already takes place avalanche-unstable process of fault formation.

According to Figure 1, fault formation avalanche process of earthquake preparation started 23 days before the earthquake.

As it was noted above, by geological model, the duration of the avalanche process of fault formation depends on the peculiarities of the region, but in general, it lasts from 10 - 14 days to 1 month. In the case of monitoring, appearing of this process on frequency records, gives us an opportunity to determine the probable time of occurring of incoming earthquake.

The study shows that detailed processing of the data in order to earthquake prediction is reasonable only from the starting moment of avalanche-unstable process.

Because avalanche-unstable process of earthquake preparation means formation 
of main fault length at the expense of cracks opening and locking in the focus of incoming earthquake, we continued searching by Formula (1) to determine character of fault length change in the focus.

Here and thereafter, the data is processed by using average square deviations:

$$
\bar{x}=\sum x_{i} \omega_{i}
$$

where $\bar{x}$ is the average numerical value and $\omega_{i}$ is the relative frequencies of $x_{i}$ data.

$$
\begin{gathered}
s^{2}=\sum \omega_{i}\left[\left(x_{i}\right)^{2}-(\bar{x})^{2}\right] \\
\sigma=\sqrt{s^{2}}
\end{gathered}
$$

$s$ and $\sigma$ are dispersion and average square deviation respectively.

Based on the above formulas, we calculated $\bar{x} \pm \sigma, \bar{x} \pm 2 \sigma$ and $\bar{x} \pm 3 \sigma$ values by every minute data of fault length in focus.

Figure 6 shows results of $\bar{x} \pm 3 \sigma$ calculation. It describes process of main fault formation in the focus well enough.

Data analysis shows that 9 - 10 days prior to the earthquake (on 14 - 15 May), it happened two main cracks locking on 8-km "cracked strip" in the 9-hour interval. We may presume that in results of it the main part of magistral (final) fault forms.

It is possible that such development of avalanche-unstable process of fault formation in time is characteristic for such magnitude earthquakes of this region. This assumption indicates the necessity of working out the retrospective data for each region in the future.

In order to improve about the 20-days forecasting method for considered earthquake, we averaged data of frequencies by 1440 minutes (1 day) and calculated relevant $\bar{X}$ and $\bar{x} \pm \sigma$ values for these data. In this case, just as before, we discussed the only period that involves the avalanche-unstable process (Figure 7).

Figure 7, similarly to Figure 1, shows that avalanche-unstable process starts 23 days before the earthquake and lasts about for 19 days, which is expressed by sharp changing of frequency values (fault length in the focus).

Such changes of frequencies should be followed by EM silence period, when almost it is not possible to fix radiation, or the main fault is already formed, on which the certain "portion" of tectonic stress is spent. Of course, the certain time

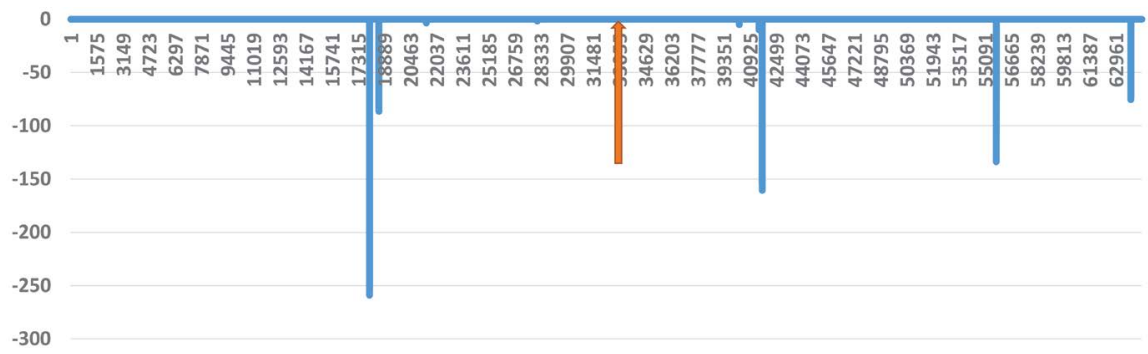

Figure 6. Fault length changes before Grete earthquake calculated by $\bar{x} \pm 3 \sigma$ value. 
is necessary for restoring of this stress "portion" [19] [21] [22] [23] [24] [32] [33]. As soon as the tectonic stress exceeds the limit of rocks strength, the earthquake occurs.

This process is clearly expressed in Figure 7, where indeed, after the avalanche-unstable process weakening, 5-days EM "silence" period appears, after which earthquake occurs.

At the next stage of the research, we tried to determine incoming earthquake occurring time with much higher accuracy. For this goal, we used the same frequency data averaged by 1440 minutes ( 1 day). After that we calculated the frequency ratios and their $\bar{x} \pm \sigma, \bar{x} \pm 2 \sigma$ and $\bar{x} \pm 3 \sigma$ values. The relevant graphs for $\bar{x} \pm \sigma$ and $\bar{x} \pm 3 \sigma$ are given on Figure 8 and Figure 9 correspondingly. The result of the research shows clear, sharp anomalous changing of frequency ratios 2-days before earthquake, which could be considered as short-term, 2-days prediction of considered earthquake.

Research analysis of Crete earthquake conducted by INFREP data confirms

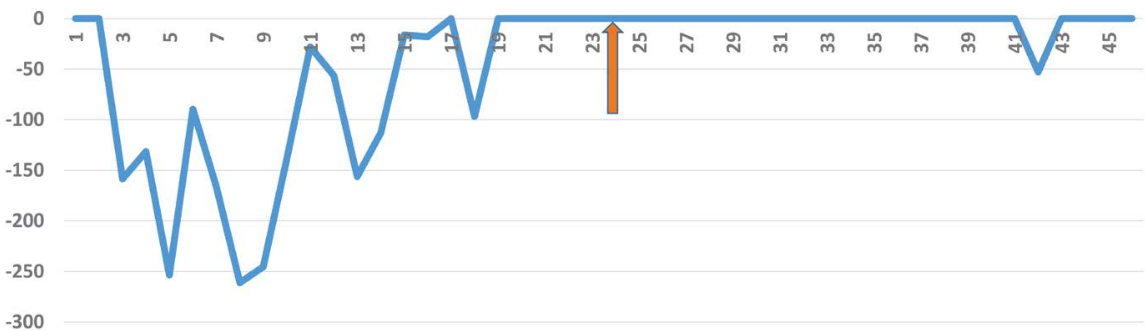

Figure 7. 19-days avalanche process of fault formation and 5-days EM emissions "silence" period before Grete earthquake calculated by frequency $\bar{x} \pm \sigma$ value.

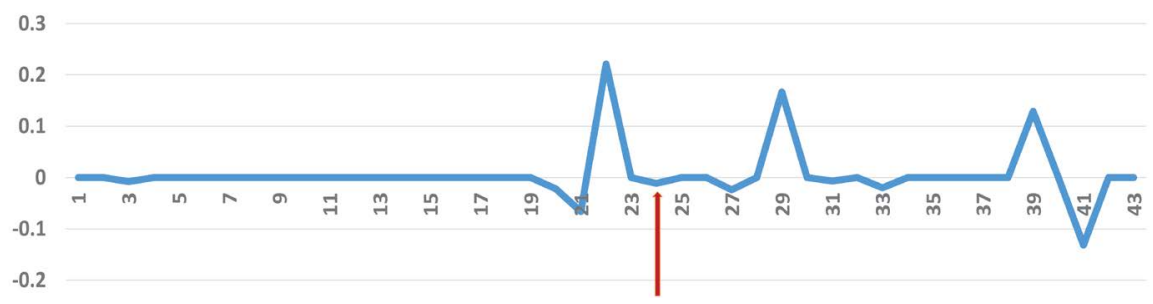

Figure 8. EM emissions "silence" period and anomaly, calculated by frequency ratios $\bar{x} \pm \sigma$ values.

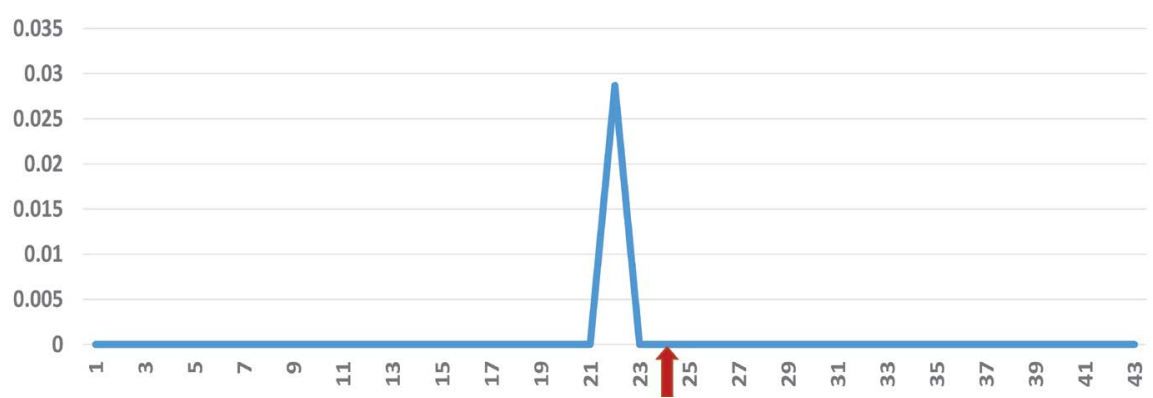

Figure 9. EM emissions "silence" period and anomaly, calculated by frequency ratios $\bar{x} \pm 3 \sigma$ values. 
the theoretical suggestions and experimental outcomes of scientific works published previously [2] [7] [11] [12] [13] [19] [20] [24].

At this stage we do not study issues concerning foreshocks and aftershocks. Although, based on suggested method it is easy to separate from each other foreshocks, main shock and aftershocks. Namely, if after any shock the frequencies of EM emissions decrease, it means that the process of earthquake preparing is not finished yet and the main shock is expected and vice versa.

Methods offered in the presented article provide large earthquake prediction possibilities in case of monitoring of earthquake preparation process.

\section{Conclusions}

Based on the INFREP data, on example of Crete 25/05/2016 08:36:13 UTC, $M=$ 5.6 earthquake, methods of large earthquake prediction have been developed, which in case of EM radiation monitoring, enable to determine epicenter, magnitude and time of occurring of incoming earthquake simultaneously.

In results of research the following conclusions are made:

1) About 50 days prior to the earthquake, it is possible to separate a continuous active frequency channel;

2) By the active channel frequency, about 50 days before the earthquake, it is possible to determine the length of "cracked strip" on which the process of cracks origination is going on actively and ultimately the main fault forms;

3) By the length of the "cracked strip", it is possible to determine magnitude of incoming earthquake with certain accuracy about 50 days prior to the earthquake;

4) After the active frequency channel detection, it is already possible to determine the future earthquake epicenter with certain accuracy;

5) In order to short-term prediction of a large earthquake, it is recommended to begin the frequency data monitoring from the starting moment of the avalanche-unstable process of fault formation and keep an eye on the process dynamics;

6) In the case of monitoring of electromagnetic emissions existent before earthquake, it is possible, step-by-step, to make about 50, 20 as well as 2-days short-term prediction of incoming earthquake;

7) Based on the proposed method, it is easy to separate the foreshock and aftershock series from the main shock;

8) EM emissions turned out to be the unique precursor, which is capable of large earthquake short-term prediction.

\section{Conflicts of Interest}

The authors declare no conflicts of interest regarding the publication of this paper.

\section{References}

[1] Biagi, P.F. (1999) Seismic Effects on LF Radiowaves. In: Hayakawa, M., Ed., At- 
mospheric and Ionospheric Electromagnetic Phenomena Associated with Earthquakes, TERRAPUB, Tokyo, 535-542.

[2] Biagi, P.F., Magippinto, T., Schiavulli, L., Ligonzo, T. and Ermini, A. (2013) European Network for Collecting VLF/LF Radio Signals (D5.1a). DPC-INGV-S3 Project. Short Term Earthquake Prediction and Preparation.

[3] Hayakawa, M., Molchanov, O.A., Ondoh, T. and Kawai, E. (1996) The Precursory Signature Effect of the Kobe Earthquake on Subionospheric VLF Signals. Journal of Communications Research Laboratory, 43, 169-180. https://doi.org/10.1109/ELMAGC.1997.617080

[4] Hayakawa, M., Ohta, K., Maekawa, S., Yamauchi, T., Ida, Y., Gotoh, T., Yonaiguchi, N., Sasaki, H. and Nakamura, T. (2006) Electromagnetic Precursors to the $2004 \mathrm{Mid}$ Niigata Prefecture Earthquake. Physics and Chemistry of the Earth, 31, 356-364. https://doi.org/10.1016/j.pce.2006.02.023

[5] Hayakawa, M. (2018) Earthquake Precursor Studies in Japan. In: Ouzounov, D., Pulinets, S., Hattori, K. and Taylor, P., Eds., Pre-Earthquake Processes: A Multidisciplinary Approach to Earthquake Prediction Studies, Geophysical Monograph 234, John Wiley \& Sons, Inc., Hoboken, 7-18.

https://doi.org/10.1002/9781119156949.ch2

[6] Hattori, K., Takahashi, I., Yoshino, C., Isezaki, N., Iwasaki, H., Harada, M., Kawabata, K., Kopytenko, E., Kopytenko, Y., Maltsev, P., Korepanov, V., Molchanov, O., Hayakawa, M., Noda, Y., Nagao, T. and Uyeda, S. (2004) ULF Geomagnetic Field Measurements in Japan and Some Recent Results Associated with Iwateken Nairiku Hokubu Earthquake in 1998. Physics and Chemistry of the Earth, 29, 481-494. https://doi.org/10.1016/j.pce.2003.09.019

[7] Freund, F.T., Takeuchi, A. and Lau, B.W.S. (2006) Electric Currents Streaming Out of Stressed Igneous Rocks-A Step towards Understanding Pre-Earthquake Low Frequency EM Emissions. Physics and Chemistry of the Earth, 31, 389-396. https://doi.org/10.1016/j.pce.2006.02.027

[8] Parrot, M. (2006) First Results of the Demeter Micro-Satellite. Planetary and Space Science, 54, 411-557. https://doi.org/10.1016/j.pss.2005.10.012

[9] Varotsos, P., Sarlis, N., Skordas, E. and Lazaridou, M. (2006) Additional Evidence on Some Relationship between Seismic Electric Signals (SES) and Earthquake Focal Mechanism. Tectonophysics, 412, 279-288. https://doi.org/10.1016/j.tecto.2005.10.037

[10] Bleier, T., Dunson, C., Maniscalco, M., Bryant, N., Bambery, R. and Freund, F. (2009) Investigation of ULF Magnetic Pulsations, Air Conductivity Changes, and Infrared Signatures Associated with the 30 October Alum Rock M5.4 Earthquake. Natural Hazards and Earth System Sciences, 9, 585-603. https://doi.org/10.5194/nhess-9-585-2009

[11] Eftaxias, K., Athanasopoulou, L., Balasis, G., Kalimeri, M., Nikolopoulos, S., Contoyiannis, Y., Kopanas, J., Antonopoulos, G. and Nomicos, C. (2009) Unfolding the Procedure of Characterizing Recorded Ultralow Frequency, $\mathrm{kHZ}$ and $\mathrm{MHz}$ Electromagnetic Anomalies Prior to the L'Aquila Earthquake as Pre-Seismic Ones-Part 1. Natural Hazards and Earth System Sciences, 9, 1953-1971.

https://doi.org/10.5194/nhess-9-1953-2009 http://www.nat-hazards-earth-syst-sci.net/9/1953/2009

[12] Contadakis, M.E., Biagi, P.F. and Hayakawa, M. (Eds.) (2009) Ground and Satellite Based Observations during the Time of the Abruzzo Earthquake. Natural Hazards and Earth System Sciences, No. 102, 151. 
http://www.nat-hazards-earth-syst-sci.net/specialissue102.html

[13] Ouzounov, D., Pulinets, S., Romanov, A., Romanov, A., Tsybulya, K., Davidenko, D., Kafatos, M. and Taylor, P. (2011) Atmosphere-Ionosphere Response to the M9 Tohoku Earthquake Revealed by Multi-Instrument Space-Borne and Ground Observations: Preliminary Results. Earthquake Science, 24, 557-564. https://doi.org/10.1007/s11589-011-0817-z

[14] Tramutoli, V., Aliano, C., Corrado, R., Filizzola, C., Genzano, N., Lisi, M., Martinelli, G. and Pergola, N. (2013) On the Possible Origin of Thermal Infrared Radiation (TIR) Anomalies in Earthquake-Prone Areas Observed Using Robust Satellite Techniques (RST). Chemical Geology, 339, 157-168. https://doi.org/10.1016/j.chemgeo.2012.10.042

[15] Kiladze, R., Kachakhidze, N., Kereselidze, Z., Kachakhidze, M., Ramishvili, G. and Kukhianidze, V. (2005) Atmospheric Pressure as an Earthquake Initiative Factor on the Example of Five Earthquakes in the Georgia. Bulletin of Georgian Academy, 171, 278-281.

[16] Kachakhidze, M., Kiladze, R., Kachakhidze, N., Ramishvili, G. and Kukhianidze, V. (2010) Connection of Large Earthquakes Occurring Moment with the Movement of the Sun and the Moon and with the Earth Crust Tectonic Stress Character. Natural Hazards and Earth System Sciences, 10, 1629-1633.

https://doi.org/10.5194/nhess-10-1629-2010

http://www.nat-hazards-earth-syst-sci.net/10/1629/2010

[17] Kachakhidze, M., Kachakhidze, N., Kiladze, R., Kukhianidze, V. and Ramishvili, G. (2003) Relatively Small Earthquakes of Javakheti Highland as the Precursors of Large Earthquakes Occurring in the Caucasus. Natural Hazards and Earth System Sciences, 3, 165-170. https://doi.org/10.5194/nhess-3-165-2003

[18] Kachakhidze, N., Kachakhidze, M., Kereselidze, Z. and Ramishvili, G. (2009) Specific Variations of the Atmospheric Electric Field Potential Gradient as a Possible Precursor of Caucasus Earthquakes. Natural Hazards and Earth System Sciences, 9, 1221-1226. https://doi.org/10.5194/nhess-9-1221-2009

[19] Kachakhidze, M.K., Kachakhidze, N.K. and Kaladze, T.D. (2015) A Model of the Generation of Electromagnetic Emissions Detected Prior to Earthquakes. Physics and Chemistry of the Earth, 85-86, 78-81. https://doi.org/10.1016/j.pce.2015.02.010

[20] Mjachkin, V.I. (1978) Earthquake Preparation Processes. Nauka, Moscow, 230.

[21] Eftaxias, K., Potirakis, S.M. and Chelidze, T. (2013) On the Puzzling Feature of the Silence of Precursory Electromagnetic Emissions. Natural Hazards and Earth System Sciences, 13, 2381-2397. https://doi.org/10.5194/nhess-13-2381-2013

[22] Papadopoulos, G.A., Charalampakis, M., Fokaefs, A. and Minadakis, G. (2010) Strong Foreshock Signal Preceding the L'Aquila (Italy) Earthquake (Mw6.3) of 6 April 2009. Natural Hazards and Earth System Sciences, 10, 19-24. https://doi.org/10.5194/nhess-10-19-2010

[23] Kachakhidze, M., Kachakhidze-Murphy, N. and Biagi, P.F. (2016) Earthquake Forecasting Possible Methodology. GESJ: Physics, No. 1(15), 102-111.

[24] Kachakhidze, M. and Kachakhidze, N. (2016) VLF/LF EM Emissions as Main Precursor of Earthquakes and Their Searching Possibilities for Georgian S/A Region. Geophysical Research Abstracts. Vol. 18, EGU2016-3280, (A).

[25] Jenkins, G.M. and Watts, D.G. (1972) Spectral Analysis and Its Applications. Mir, M, 287 p. (In Russian)

[26] Dobrovolsky, I.P., Zubkov, S.I. and Mjachkin, V.I. (1979) Estimation of the Size of 
Earthquake Preparation Zones. Pure and Applied Geophysics, 117, 1025-1044. https://doi.org/10.1007/BF00876083

[27] Moldovan, I.A., Placinta, A.O., Constantin, A.P., Moldovan, A.S. and Ionescu, C. (2012) Correlation of Geomagnetic Anomalies Recorded at Muntele Rosu Seismic Observatory (Romania) with Earthquake Occurrence and Solar Magnetic Storms. Annales Geophysicae, 55, 125-137.

[28] Dudkin, F., Korepanov, V., Hayakawa, M. and De Santis, A. (2013) Possible Model of Electromagnetic Signals before Earthquakes. In: Arabelos, D., Kaltsikis, C., Spatalas, S. and Tsiavos, I.N., Eds., “Thales", Volume Dedicated to Prof. Emeritus M. E. Contadakis, Chapter. 2. Geosciences, Ziti Publishing, Thessaloniki, 159-170. http://www.topo.auth.gr/greek/ORG DOMI/EMERITUS/TOMOS CONTADAKIS Contadakis Honorary Volume.htm

[29] Hayakawa, M., Hobara, Y., Rozhnoi, A., Solovieva, M., Ohta, K., Izutsu, J., Nakamura, T., Yasuda, Y., Yamaguchi, H. and Kasahara, Y. (2013) The Ionospheric Precursor to the 2011 March 11 Earthquake as Based on the Japan-Pacific Subionospheric VLF/LF Network Observation. Telecommunications and Radio Engineering, 71, 1687-1706. https://doi.org/10.1615/TelecomRadEng.v71.i18.60 http://www.topo.auth.gr/greek/ORG DOMI/EMERITUS/TOMOS CONTADAKIS /Contadakis Honorary Volume.htm

[30] Kachakhidze, M., Kachakhidze, N. and Kaladze, T. (2015) Explanation of Lithosphere-Atmosphere-Ionosphere Coupling System Anomalous Geophysical Phenomena on the Bases of the Model of Generation of Electromagnetic Emissions Detected before Earthquake. GES): Physics, 2, 66-75.

[31] Ouzounov, D., Pulinets, S., Hattori, K. and Taylor, P. (2018) Pre-Earthquake Processes: A Multidisciplinary Approach to Earthquake Prediction Studies. Wiley, Hoboken.

[32] Johnston, M. (1997) Review of Electric and Magnetic Fields Accompanying Seismic and Volcanic Activity. Surveys in Geophysics, 18, 441-475.

https://doi.org/10.1023/A:1006500408086

[33] Boudjada, M.Y., Schwingenschuh, K., Döller, R., Rohznoi, A., Parrot, M., Biagi, P.F., Galopeau, P.H.M., Solovieva, M., Molchanov, O., Biernat, H.K., Stangl, G., Lammer, H., Moldovan, I., Voller, W. and Ampferer, M. (2010) Decrease of VLF Transmitter Signal and Chorus-Whistler Waves before l'Aquila Earthquake Occurrence. Natural Hazards and Earth System Sciences, 10, 1487-1494.

https://doi.org/10.5194/nhess-10-1487-2010 